OAK RIDGE

NATIONAL LABORATORY

MANAGED BY UT-BATTELLE

FOR THE DEPARTMENT OF ENERGY

\title{
ASSESSMENT OF REUSING 14-TON, THIN-WALL, DEPLETED UF 6 CYLINDERS AS LLW DISPOSAL CONTAINERS
}

D. G. O'Connor

\author{
A. B. Poole
}

J. H. Shelton

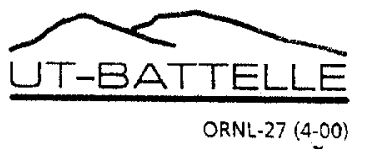



DEPLETED UF 6 CYLINDERS AS LLW DISPOSAL CONTAINERS

D. G. O'Connor

A. B. Poole

J. H. Shelton

Date Published: November 2000

Prepared by

OAK RIDGE NATIONAL LABORATORY

Oak Ridge, Tennessee 37831-6285

managed by

UT-BATTELLE, LLC

for the

U.S. DEPARTMENT OF ENERGY

under contract DE-AC05-00OR22725 


\section{CONTENTS}

Page

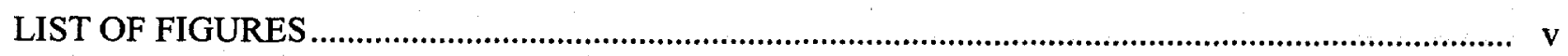

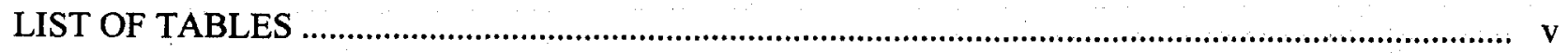

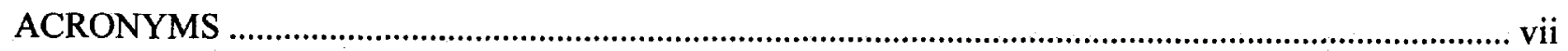

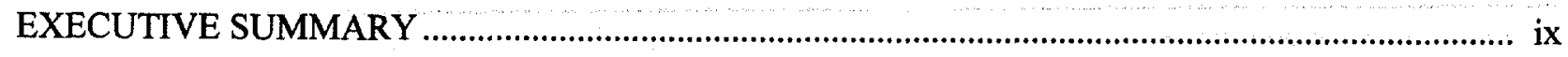

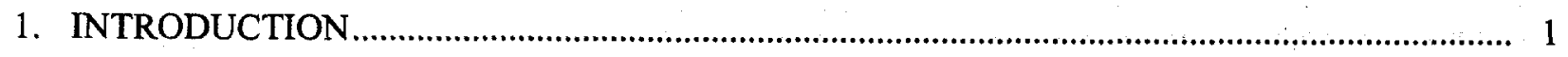

2. STRUCTURAL ASSESSMENT OF 14-TON, THIN-WALL CYLINDERS ................................. 2

3. OUTLINE FOR DEVELOPING A PROCEDURE FOR FILLING 14-TON, THIN-WALL

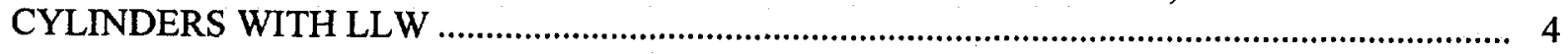

4. TRANSPORTATION REQUIREMENTS FOR CYLINDERS USED AS LLW CONTAINERS... 8

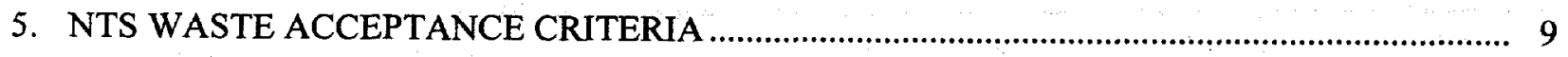

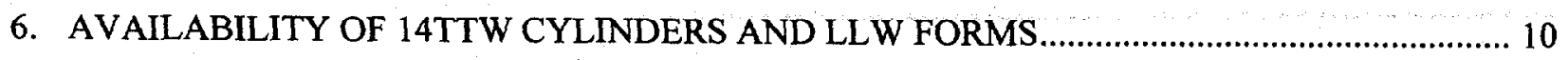

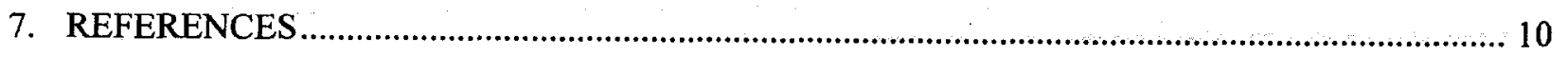




\section{LIST OF FIGURES}

\section{Figure}

Page

1. Sketch of DUF 6 cylinders stored in the yard. Typical cylinder row section (Ref. 6)..................... 3

2. Sketch of DUF 6 cylinders stored in the yard. Typical cylinder yard section (Ref. 6).................... 4

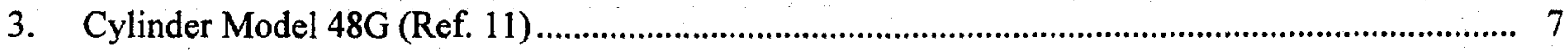

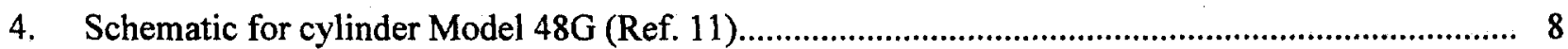

\section{LIST OF TABLES}

Table $\quad$ Page

1. Estimate of the volume of LLW that could be disposed of in 14TTW cylinders......................... 6

2. Approximate volume of available 14TTW cylinders........................................................ 9 


\section{ACRONYMS}

14TTW 14-ton, thin-wall cylinders

ANSI

American National Standards Institute

ASME

American Society of Mechanical Engineers

BJC

Bechtel Jacobs Company, LLC

CFR

Code of Federal Regulations

DOE

Department of Energy

DOE/NV

DOT

DU

Department of Energy Nevada Operations Office

Department of Transportation

$\mathrm{DUF}_{6}$

ETTP

depleted uranium

depleted uranium hexafluoride

LSA

East Tennessee Technology Park

LLW

low specific activities

MT

NTS

low-level waste

metric tonne

NTSWAC Nevada Test Site Waste Acceptance Criteria

ORNL

RWAP

STC

$\mathrm{UF}_{6}$

Oak Ridge National Laboratory

Radioactive Waste Acceptance Program

strong tight container

USEC

uranium hexafluoride

WAC

United States Enrichment Corporation

Waste Acceptance Criteria 


\section{EXECUTIVE SUMMARY}

Approximately $700,000 \mathrm{MT}$ of $\mathrm{DUF}_{6}$ is stored, or will be produced under a current agreement with the USEC, at the Paducah site in Kentucky, Portsmouth site in Ohio, and ETTP site in Tennessee. On July 21,1998 , the $105^{\text {th }}$ Congress approved Public Law 105-204, which directed that facilities be built at the Kentucky and Ohio sites to convert DUF $_{6}$ to a stable form for disposition. On July 6, 1999, the Department of Energy (DOE) issued the Final Plan for the Conversion of Depleted Uranium Hexafluoride as Required by Public Law 105-204 in which DOE committed to develop a Depleted Uranium Hexafluoride Materials Use Roadmap. On September 1, 2000, DOE issued the Draft Depleted Uranium Hexafluoride Materials Use Roadmap (Roadmap), which provides alternate paths for the longterm storage, beneficial use, and eventual disposition of each product form and material that will result from the DUF 6 conversion activity. One of the paths being considered for DUF $_{6}$ cylinders is to reuse the empty cylinders as containers to transport and dispose of low-level waste (LLW), including the converted DU. The Roadmap provides results of the many alternate uses and disposal paths for conversion products and the empty DUF 6 storage cylinders. As a part of the Roadmap, evaluations were conducted of cost savings, technical maturity, barriers to implementation, and other impacts. Results of these evaluations indicate that using the $\mathrm{DUF}_{6}$ storage cylinders as LLW disposal containers could provide moderate cost savings due to the avoided cost of purchasing LLW packages and the avoided cost of disposing of the cylinders. No significant technical or institutional issues were identified that would make using cylinders as LLW packages less effective than other disposition paths.

Over 58,000 cylinders have been used, or will be used, to store DUF 6 . Over 51,000 of those cylinders are 14-ton, thin-wall $(14 \mathrm{TTW})$ cylinders with a nominal wall thickness of $5 / 16$-in. $(0.79 \mathrm{~cm})$. These 14TTW cylinders, which have a nominal diameter of 48 inches and nominally contain 14 tons (12.7 MT)

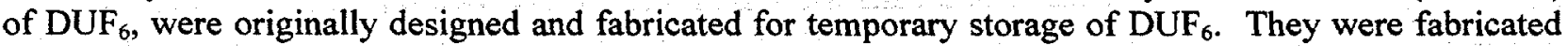
from pressure-vessel-grade steels according to the provisions of the ASME Boiler and Pressure Vessel Code. Cylinders are stored in open yards at the three sites and, due to historical storage techniques, were subject to corrosion. Roughly 10,000 of the 14TTW cylinders are considered substandard due to corrosion and other structural anomalies caused by mishandling. This means that approximately 40,000 14TTW cylinders could be made available as containers for LLW disposal.

In order to demonstrate the use of 14TTW cylinders as LLW disposal containers, several qualifying tasks need to be performed. Two demonstrations are being considered using 14TTW cylinders-one demonstration using contaminated soil and one demonstration using $\mathrm{U}_{3} \mathrm{O}_{8}$. The objective of this report are to determine how much information is known that could be used to support the demonstrations, and how much additional work will need to be done in order to conduct the demonstrations. Information associated with the following four qualifying tasks are evaluated in this report.

- Perform a review of structural assessments that have been conducted for 14TTW.

- Develop a procedure for filling 14TTW cylinders with LLW that have been previously washed.

- Evaluate the transportation requirements for shipping 14TTW cylinders containing LLW.

- Evaluate the waste acceptance criteria (WAC) that will be imposed by the Nevada Test Site (NTS).

In order to fill 14TTW cylinders with LLW, the cylinders will need to be modified. A hole will need to be made in the cylinder wall to allow loading of the LLW, and a patch will need to be welded over the access hole. To minimize the impact of this process to the structural integrity of the cylinder, it is preferred to place the hole at a location that experiences low-stress levels during normal handling and storage operations. A review was conducted of two reports to determine what areas of the cylinder would be better candidate locations for placement of a hole. No new structural analyses were conducted to support this report. 
DUF $_{6}$ cylinders currently meet the DOT requirements for transport of DUF . Given that the objective of this report is to evaluate using 14TTW cylinders as LLW containers for $\mathrm{U}_{3} \mathrm{O}_{8}$ and contaminated soil, it is reasonable to assume, for the purposes of this report, that these cylinders will also be acceptable packages to transport these waste forms.

Based on structural analyses conducted by Battelle and Oak Ridge National Laboratory to support the DUF $_{6}$ Cylinder Management Program, filling 14TTW cylinders with LLW is not likely to result in structural problems as long as the LLW weighs less than the allowable limit of DUF 6 .

Bechtel Jacobs Company, LLC (BJC) Procedure FS-B-2403, Rev. 1, Weld Patch Repair of Large Diameter DOE UF 6 Cylinders, provides a basis to establish a reasonable path forward for using 14TTW cylinders as LLW containers. This procedure was developed for the purpose of performing repairs to cylinders that includes cylinders that have corroded or been damaged to the point that a breach has occurred, exposing the cylinder contents to the outside environment. Since only cylinders that are acceptable for DUF $_{6}$ transport and show no signs of unacceptable damage will be used as LLW containers, an acceptable procedure and plan developed to modify, fill, and seal 14TTW cylinders and transport the LLW-filled cylinders to NTS for final disposal is a reasonable expectation.

A review of the Department of Transportation (DOT) regulations revealed 14TTW cylinders would meet the specifications for a strong tight container and could be used to ship low specific activities (LSA) materials, which is a type of LLW.

A review of the process for developing and satisfying the WAC for NTS, and as a result of discussions with NTS staff, it is reasonable to believe that 14TTW cylinders filled with LSA LLW would be an acceptable waste form for final disposal in Area 3.

In order to fully develop and prove feasibility of using 14TTW cylinders as LLW containers that can be disposed of at NTS, a demonstration activity must be conducted by DOE. Using 14TTW cylinders in this way will greatly reduce the disposal costs associated with the cylinders for the Depleted Uranium Disposition Program. These cylinders may also prove valuable to LLW generators needing large packages that would be acceptable to NTS. 


\section{INTRODUCTION}

Approximately $700,000 \mathrm{MT}$ of $\mathrm{DUF}_{6}$ is stored, or will be produced under a current agreement with the USEC, at the Paducah site in Kentucky, Portsmouth site in Ohio, and ETTP site in Tennessee. On July 21,1998 , the $105^{\text {th }}$ Congress approved Public Law 105-204 (Ref. 1), which directed that facilities be built at the Kentucky and Ohio sites to convert DUF $_{6}$ to a stable form for disposition. On July 6, 1999, the Department of Energy (DOE) issued the Final Plan for the Conversion of Depleted Uranium Hexafluoride as Required by Public Law 105-204 (Ref. 2), in which DOE committed to develop a Depleted Uranium Hexafluoride Materials Use Roadmap. On September 1, 2000, DOE issued the Draft Depleted Uranium Hexafluoride Materials Use Roadmap (Ref. 3) (Roadmap), which provides alternate paths for the long-term storage, beneficial use, and eventual disposition of each product form and material that will result from the $\mathrm{DUF}_{6}$ conversion activity. One of the paths being considered for $\mathrm{DUF}_{6}$ cylinders is to reuse the empty cylinders as containers to transport and dispose of LLW, including the converted DU. The Roadmap provides results of the many alternate uses and disposal paths for conversion products and the empty DUF $_{6}$ storage cylinders. As a part of the Roadmap, evaluations were conducted of cost savings, technical maturity, barriers to implementation, and other impacts. Results of these evaluations indicate that using the DUF $_{6}$ storage cylinders as LLW disposal containers could provide moderate cost savings due to the avoided cost of purchasing LLW packages and the avoided cost of disposing of the cylinders. No significant technical or institutional issues were identified that would make using cylinders as LLW packages less effective than other disposition paths.

Over 58,000 cylinders have been used, or will be used, to store DUF $_{6}$. Over 51,000 of those cylinders are $14 \mathrm{TTW}$ cylinders with a nominal wall thickness of $5 / 16$-in. $(0.79 \mathrm{~cm})$. These 14TTW cylinders, which have a nominal diameter of 48 inches and nominally contain 14 tons (12.7 MT) of DUF , were $^{2}$ originally designed and fabricated for temporary storage of DUF 6 . They were fabricated from pressurevessel-grade steels according to the provisions of the ASME Boiler and Pressure Vessel Code (Ref. 4). Cylinders are stored in open yards at the three sites and, due to historical storage techniques, were subject to corrosion. Roughly 10,000 of the 14TTW cylinders are considered substandard (Ref. 5) due to corrosion and other structural anomalies caused by mishandling. This means that approximately 40,000 14TTW cylinders could be made available as containers for LLW disposal.

In order to demonstrate the use of 14TTW cylinders as LLW disposal containers, several qualifying tasks need to be performed. Two demonstrations are being considered using 14TTW cylinders-one demonstration using contaminated soil and one demonstration using $\mathrm{U}_{3} \mathrm{O}_{8}$. The objective of this report are to determine how much information is known that could be used to support the demonstrations, and how much additional work will need to be done in order to conduct the demonstrations. Information associated with the following four qualifying tasks are evaluated in this report.

- Perform a review of structural assessments that have been conducted for 14TTW.

- Develop a procedure for filling 14TTW cylinders with LLW that have been previously washed.

- Evaluate the transportation requirements for shipping 14TTW cylinders containing LLW.

- Evaluate the WAC that will be imposed by the NTS.

Two assumptions are made to facilitate this evaluation of using DUF $_{6}$ cylinders as LLW disposal containers.

1. Only $14 T T W$ cylinders will be considered for use as LLW containers.

2. The NTS will be the LLW disposal site. 


\section{STRUCTURAL ASSESSMENT OF 14-TON, THIN-WALL CYLINDERS}

In order to fill 14TTW cylinders with LLW, the cylinders will need to be modified. A hole will need to be made in the cylinder wall to allow loading of the LLW, and a patch will need to be welded over the access hole. To minimize the impact of this process to the structural integrity of the cylinder, it is preferred to place the hole at a location that experiences low-stress levels during normal handling and storage operations. A review was conducted of two reports (Refs. 6 and 7) to determine what areas of the cylinder would be better candidate locations for placement of a hole. No new structural analyses were conducted to support this report.

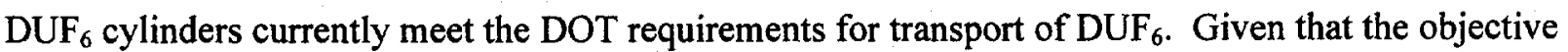
of this report is to evaluate using 14TTW cylinders as LLW containers for $\mathrm{U}_{3} \mathrm{O}_{8}$ and contaminated soil, it is reasonable to assume, for the purposes of this report, that these cylinders will also be acceptable packages to transport these waste forms. An additional limitation that will be assumed is that the14TTW cylinders will not be loaded with more material, by weight, than they were originally certified to hold.

Structural analyses have been conducted on 14TTW cylinders for a variety of conditions including:

- Static conditions-cylinders resting on chocks, stacked two-high in storage yards

- stresses at the cylinder to chock interface for stacked cylinders

- stresses at the cylinder to stiffening ring interface for stacked cylinders

- Dynamic conditions

- cylinders subject to seismic loads in storage yards

- handling loads due to mishandling

- Corroded cylinders - increased stresses for static and dynamic loading conditions

A structural integrity analysis of $\mathrm{UF}_{6}$ storage cylinders was conducted for DOE by Battelle (Ref. 6) in 1992. The purpose of the study was to conduct summary level structural analyses for 14TTW cylinders. The study had the following objectives:

- determine the punching shear force requirements;

- determine the actual stress vs allowable stresses for normal anticipated stacking-type loading conditions;

- determine the minimum thickness that can be allowed for a 3-in.-diameter thinned area; and

- determine the allowable loads for dynamic loading due to transport, lifting/stacking impacts, and seismic conditions.

Three of the results are significant to this activity:

- global stresses were extremely small for 14TTW cylinders, only local stresses were of concern;

- for static loading, the ring-to-cylinder contact loads resulted in the highest stresses at the toe of the fillet weld, and the worst case stresses were below the ASME local allowable stresses; and

- stress maps indicate the stress gradient is very steep at the toe of the fillet weld with the low stress levels at a very short distance from the fillet weld.

Results from Ref. 6 indicate that stresses would be low at the end region of the cylinder where a hole would be cut to fill the cylinder with LLW before welding a plate over the opening.

Figures 1 and 2 (taken from Ref. 6) provide illustrations as to how cylinders are currently stored and how these cylinders could possibly be stored while awaiting shipment to NTS after being filled with LLW.

A series of additional structural analyses were conducted in 1995 and 1996 and are summarized in ORNL/TM-13308, Methods and Results for Stress Analyses on 14-Ton, Thin-Wall Depleted UF 6 Cylinders (Ref. 7). The purpose of this study was to determine how much corrosion can occur before the 
structural integrity of the cylinders is compromised during routine handling and shipping operations, and how to handle damaged cylinders in such a way to minimize the possibility of a breach.

Results of Ref. 7 support the findings of Ref. 6 . In addition, the following results from Ref. 7 suggest stresses would be low at the valve location and ways to minimize stress during handling and storage.

- Stresses are minimized by placing chocks as close to the stiffening rings as possible.

- Cylinders with shells as thin as 1/16-in. can be safely lifted.

- Cylinders should be stacked with the stiffening rings as close together as possible.

- The valve location is a low stress area.

Results from Ref. 7 also indicate that stresses would be low at the end region of the cylinder where the valve is located, and a hole could be cut to fill the cylinder with LLW before welding a plate over the opening.

Based on these findings, filling 14TTW cylinders with LLW is not likely to result in structural problems, as long as the LLW weighs less than the allowable limit of DUF 6 .

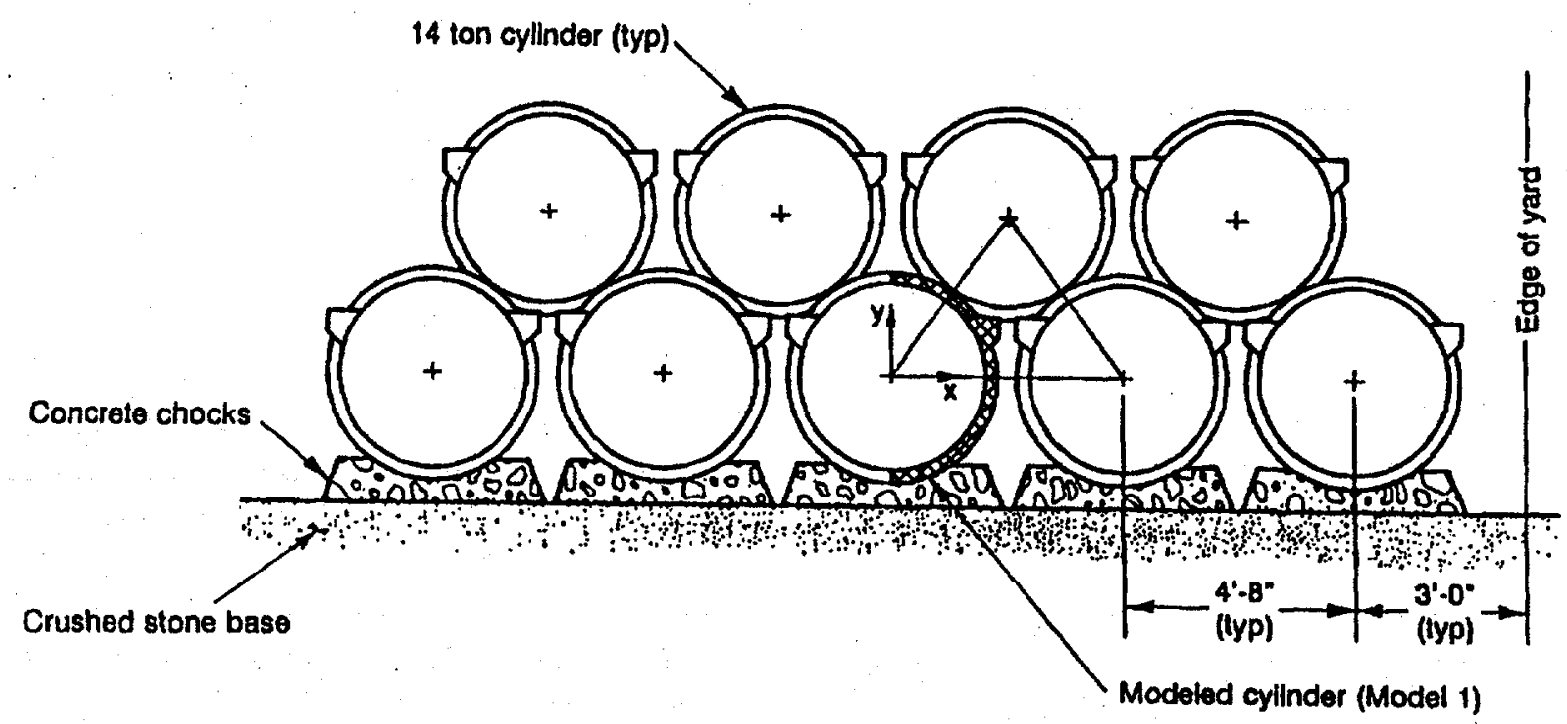

Fig. 1. Sketch of DUF 6 cylinders stored in the yard. Typical cylinder row section (Ref. 6). 


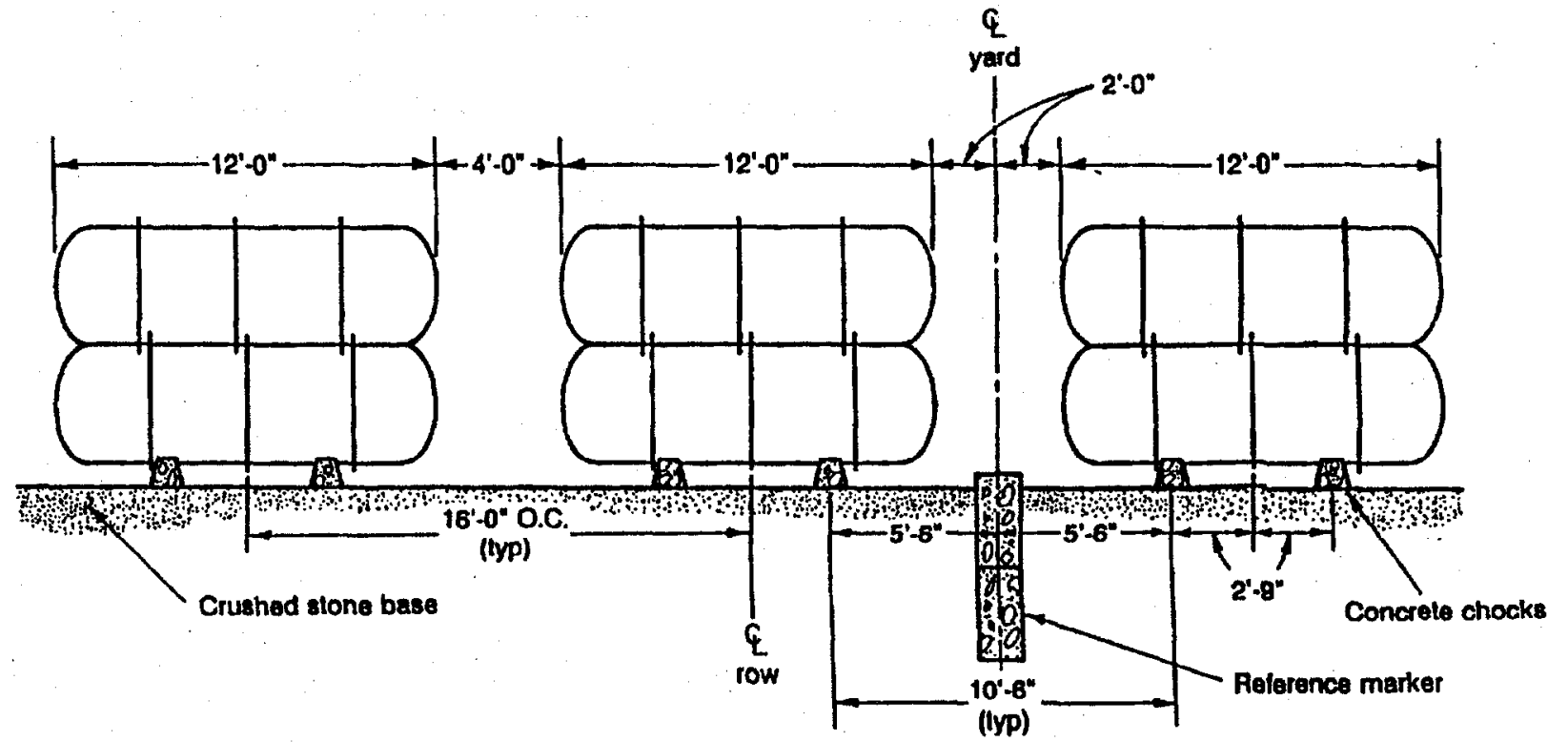

Fig. 2. Sketch of DUF 6 cylinders stored in the yard. Typical cylinder yard section (Ref. 6).

\section{OUTLINE FOR DEVELOPING A PROCEDURE FOR FILLING 14-TON, THIN-WALL CYLINDERS WITH LLW}

Development of a final procedure for filling a 14TTW cylinder with LLW will be performed in conjunction with BJC once DOE decides to proceed with a demonstration of this alternative. The purpose of this section is to provide a summary of the information needed for modifying, filling, and sealing procedures and to show that a reasonable path exists to allow 14TTW cylinders to be used as LLW containers.

BJC Procedure FS-B-2403, Rev. 1, Weld Patch Repair of Large Diameter DOE UF ${ }_{6}$ Cylinders (Ref. 8), provides a basis to establish a reasonable path forward for using 14TTW cylinders as LLW containers. This procedure was developed for the purpose of performing repairs to cylinders that includes cylinders that have corroded or been damaged to the point that a breach has occurred, exposing the cylinder contents to the outside environment. Since only cylinders that are acceptable for DUF 6 transport and show no signs of unacceptable damage will be used as LLW containers, an acceptable procedure and plan developed to modify, fill, and seal 14TTW cylinders and transport the LLW-filled cylinders to NTS for final disposal is a reasonable expectation.

In order to use 14TTW cylinders as LLW container, additional steps or activities are needed that are not stated in Ref. 8. Following is a summary list of the types of additional activities that will be needed.

- Ensure the 14TTW cylinders are empty, have been washed, and residual contamination characterized.

- Certify the minimum wall thickness is at least 0.25 in. (required to transport $\mathrm{UF}_{6}$ cylinders).

- Design and build a "tilt stand" to support 14TTW cylinders while filling.

- Cut a hole (size and shape to be determined) in the 14TTW cylinder at the valve location to provide an entry port for LLW. 
- Ensure no more than an allowed amount (by volume or weight) of acceptable LLW is put in 14TTW cylinders.

- Weld a patch over the opening that was cut in the 14TTW cylinder.

The following is a list of the design documents that are necessary to modify, fill, and seal 14TTW cylinders filled with LLW. These documents are needed to address technical, safety, and health issues.

- Cylinder Handling and Support.

- Site Layout.

- Weather Protection-for workers and cylinder.

- Hole Cutting - environmental, safety, health, radiological, and metal cutting issues will be addressed as well as disposal of the section of the cylinder wall and valve that are removed.

- Tilt Stand-to support cylinders in an inclined orientation to allow the cylinders to be filled more completely.

- LLW Characterization-14TTW cylinders will be classified as strong tight containers and the appropriate LLW form must be chosen as well as ensuring material compatibility with the steel cylinders.

- Cylinder Filling-minimize spillage and contamination and ensure cylinders are not overfilled (i.e., weight limit is not exceeded).

- Patch Design.

- Welding-ensure an appropriate procedure is followed, qualified personnel are employed, and quality and inspection documentation is prepared.

- Contamination Evaluation-establish acceptable limits for contamination and inspection methods; after welding the patch on the cylinder, inspect the exterior of the cylinder for contamination and, if contamination is found, ensure the exterior of the cylinder is decontaminated; and establish decontamination methods.

Several additional analyses and plans will be needed for acceptance of NTS (Ref. 10):

- Activity Hazards Analysis,

- Waste Management Plan,

- Inspection Plan, and

- Environmental Monitoring Plan

Several design documents, plans, and procedures have been developed as a part of the Cylinder Management Program that are appropriate for execution of this demonstration project, such as cylinder handling and storage procedures. The additional design documents, plans, and analyses listed above will be developed by a team that consists mainly of BJC staff. The team will consist of at least the following members:

- demonstration project manager,

- cylinder program manager,

- quality evaluation (ultrasonic) technicians,

- health physics,

- industrial hygiene,

- occupational safety,

- environmental protection,

- waste management,

- code inspectors, 
- quality assurance,

- engineering,

- cylinder handlers,

- mechanics, and

- welders.

To support this demonstration, a qualified team of support and craft personnel will be assembled:

- program manager,

- team coordinator,

- site engineer,

- health and safety,

- mechanics,

- welders,

- cylinder handlers,

- riggers,

- planners,

- metal fabricators,

- quality inspectors, and

- carpenters.

One of the design criteria that must be considered is the volume of LLW that can be disposed of in a 14TTW cylinder. Assuming the LLW is compatible with the steel cylinder and the waste form is acceptable for a strong tight container, the LLW volume that can be disposed of in a 14TTW cylinder will be a function of the density of the LLW. Figure 3 provides specifications for a 14TTW cylinder that indicate the minimum volume is $139 \mathrm{ft}^{3}\left(3.94 \mathrm{~m}^{3}\right)$ and the maximum net weight is $28,000 \mathrm{lb}(12.701 \mathrm{MT})$ for a model $48 \mathrm{G}$ (14TTW) cylinder (Ref. 11).

The cost of disposing of LLW at NTS is based on volume. Table 1 provides an estimate of the volume of $\mathrm{LLW}$ in the form of soil and $\mathrm{U}_{3} \mathrm{O}_{8}$ that could be placed in a 14TTW cylinder for disposal. Two significant observations can be made from Table 1. First, cylinders loaded with soil could utilize the full volume of the cylinders, regardless of the density of the soil. Second, cylinders loaded with $\mathrm{U}_{3} \mathrm{O}_{8}$ might not utilize the full volume of the cylinders and would be limited by weight. Using the example shown in Table 1 for $\mathrm{U}_{3} \mathrm{O}_{8}$, approximately 81 to $100 \%$ of the $14 \mathrm{TTW}$-cylinder volume would be utilized. Depending on the morphology and compaction of the $\mathrm{U}_{3} \mathrm{O}_{8}$ loaded into the cylinder, more or less of the cylinder volume would be utilized due to the varying density of the $\mathrm{U}_{\mathrm{e}} \mathrm{O}_{8}$. When loading $\mathrm{U}_{3} \mathrm{O}_{8}$ in cylinders, it will be required to monitor the weight to ensure cylinders are not overloaded. Weight will be limited to $12.701 \mathrm{MT}$ of LLW, the current limit of DUF $_{6}$ that can be put in a 14TTW cylinder.

Table 1. Estimate of the volume of LLW that could be disposed of in 14TTW cylinders

\begin{tabular}{cccc}
\hline LLW form & LLW density range & Weight range & Volume Range \\
\hline Soil & $1.3-2.4 \mathrm{MT} / \mathrm{m}^{3}$ (Ref. 12) & $5.1-9.5 \mathrm{MT}$ & $3.94 \mathrm{~m}^{3}$ \\
$\mathrm{U}_{3} \mathrm{O}_{8}$ & $1.5-4.0 \mathrm{MT} / \mathrm{m}^{3}$ (Ref. 13) & $12.701 \mathrm{MT}$ & $3.17-3.94 \mathrm{~m}^{3}$ \\
\hline
\end{tabular}

Figure 4 provides a schematic of a Model $48 \mathrm{G}$ cylinder (Ref. 11). The hole that would be cut in the end of the cylinder to allow the LLW to be loaded would be located at the valve. Placing the loading hole 
at the valve location accomplishes two functions. First, the valve would be removed, which would eliminate the possibility off accidently breaking the valve off during handling and transport causing a breach of the container. Second, by cutting a hole in the end of the cylinder and placing the cylinder on a tilt stand, the cylinder could be more completely filled.

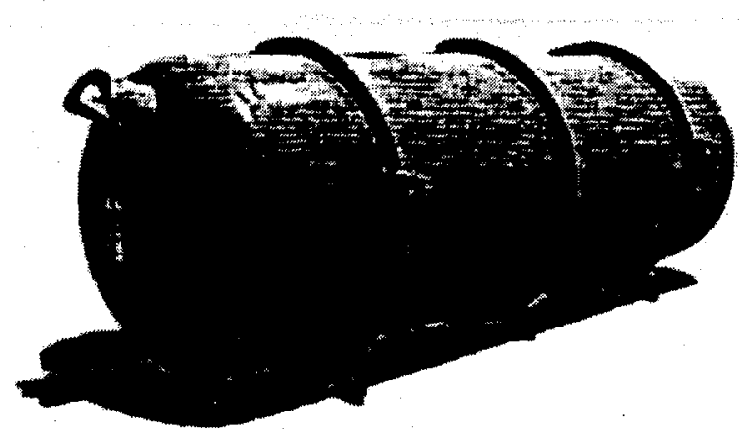

Nominal Diameter 48 in. $(122 \mathrm{~cm})$

Nominal Length $146 \mathrm{in} .(370 \mathrm{~cm})$

Nominal Wall Thickness. $5 / 16$ in. $(0.8 \mathrm{~cm})$

Nominal Tare Weight. $2,600 \mathrm{lb}(1,179 \mathrm{~kg})$

Maximum Net Weight $28,000 \mathrm{lb}(12,701 \mathrm{~kg})$

Nominal Gross Weight. $.30,600 \mathrm{lb}(13,800 \mathrm{~kg})$

Minimum Volume. $139 \mathrm{ft}^{3}\left(3.94 \mathrm{~m}^{3}\right)$

Basic Material of Construction Steel**

Service Pressure 100 psig (690 kPa gage)

Hydrostatic Test Pressure. 200 psig (1380 kPa gage) Isotopic Content aLimit $1 \%{ }^{235} \mathrm{U}$

Valve Used-1-in. valve.

Note: Primarily used for depleted UF 6 storage. Cylinders with serial numbers below 111821 do not have certified volumes. An earlier design was designated Model OM.

* Based on $235^{\circ} \mathrm{F}\left(113^{\circ} \mathrm{C}\right)$.

** Steel specification changed from A-285 to A-516 for cylinders ordered after 1978.

Fig. 3. Cylinder Model 48G (Ref. 11). 


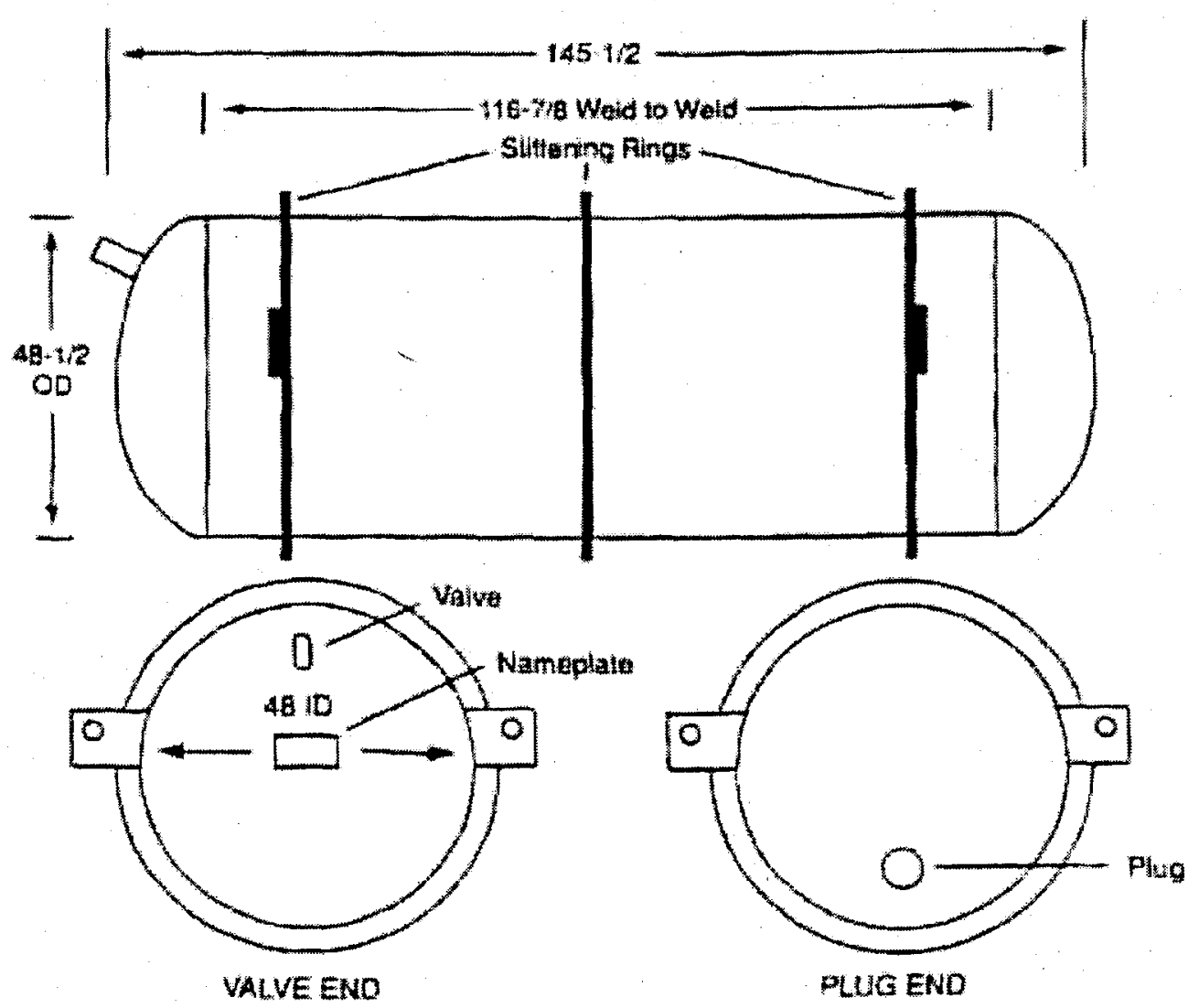

Fig. 4. Schematic for cylinder Model 48G (Ref. 11).

\section{TRANSPORTATION REQUIREMENTS FOR CYLINDERS USED AS LLW CONTAINERS}

All DOT packagings are based on the classification of the material contained in the package. Depleted uranium or contaminated soil, in most cases, will meet DOT's definition ofLSA material. This material can be transported domestically in strong tight containers (STCs) per 49 CFR 173.427(b)(3) (Ref. 9). STC requirements are found in 49 CFR 173.24 and 173.410 (Ref. 9). Both sections have specific requirements for strong tight containers, but in short, these two sections simply define a package that will prevent leakage of radioactive content under normal conditions of transport. There are no American National Standards Institute (ANSI) standards or tests requirements for STCs.

State regulations for radioactive material transport normally defer to the federal regulations (Ref. 9). ORNL complies with federal regulations to ship all radioactive material shipments that are made across the country. ORNL and BJC currently ship LLW to NTS using the 49 CFR 173 regulations. State inspectors review each package prior to shipment.

Based on a review of the regulations (Ref. 11), 14TTW cylinders would meet DOT's definition of a STC and could be used to ship LLW soil and $\mathrm{U}_{3} \mathrm{O}_{8}$ that are classified as LSA material after verification of the integrity of the steel cylinder and assurances that the cylinders have been properly sealed. 


\section{NTS WASTE ACCEPTANCE CRITERIA}

Disposal of 14TTW cylinders as LLW requires that the waste form and package meet WAC for the Nevada Test Site Waste Acceptance Criteria (NTSWAC). These requirements are conceptually the same for all disposal facilities but vary in detail because of differing site characteristics and disposal operations. The process for demonstrating compliance with waste acceptance requirements can be time-consuming and costly unless the requirements are coordinated with the selection of the waste form and package. Based upon the analysis provided in Ref. 15 on DU disposal and discussion with Bechtel at NTS (Ref. 16), 14TTW cylinders used as LLW packages should meet NTSWAC requirements.

The NTS has two low-level radioactive waste disposal facilities. The Area 3 disposal facility is located in Yucca Flat and uses subsidence craters from past underground nuclear tests as disposal cells. This facility accepts uncontainerized wastes and large bulk containers of waste. The current and planned capacity in Area 3 is nearly 4 million cubic meters. The Area 5 disposal facility is located in Frenchman Flat and uses shallow land burial technology for disposal. Area 5 accepts containerized waste such as boxes and drums. The current and planned capacity in Area 5 is over 3 million cubic meters (Ref. 15). Consequently, the projected capacity required for 14TTW LLW containers (approximately $160,000 \mathrm{~m}^{3}$; Table 2) would be accommodated at the NTS.

Table 2. Approximate volume of potential 14TTW cylinders

\begin{tabular}{ccc}
\hline $\begin{array}{c}\text { Volume of } \\
\text { 14TTW cylinder }\end{array}$ & $\begin{array}{c}\text { Number of } \\
\text { cylinders }\end{array}$ & Total expected volume \\
\hline $4 \mathrm{~m}^{3}\left(140 \mathrm{ft}^{3}\right)$ & 40,000 & $160,000 \mathrm{~m}^{3}\left(5,600,000 \mathrm{ft}^{3}\right)$ \\
\hline
\end{tabular}

As noted in Ref. 15, wastes accepted for disposal in Areas 3 and 5 must meet the NTSWAC (Ref. 12). These criteria require separate processes for approval of generators and waste streams by the DOE Nevada Operations Office (DOE/NV). The approval process is described in detail in the NTSWAC. The process includes the documentation requirements for the waste generator and the Radioactive Waste Acceptance Program (RWAP) Review performed by DOE/NV. The purpose of the program review is to ensure that the provisions of the NTSWAC can and will be met by the generator. The approval process consists of the following:

- The initial waste generator approval review-This review examines the generator's proposed implementation of the NTSWAC. As noted earlier, both ORNL and BJC currently dispose of LLW at NTS.

- The waste profile approval process-The waste profile summarizes the characterization and the NTSWAC compliance of a waste stream. The waste profile must be prepared by the generator and approved by DOE/NV prior to shipment of waste to the NTS for disposal. The review process supporting the DOE/NV approval decision includes examination of the profile of each waste stream proposed for disposal by the NTS Waste Acceptance Review Panel, which may (1) require the development of additional information, (2) recommend the waste stream for approval, and/or (3) recommend surveillance of the waste stream at the generator's site.

- Facility evaluations-These evaluations include a triennial audit of compliance with the NTSWAC, an annual assessment of a generator's program, and surveillance when appropriate.

RWAP personnel recommend approval to DOE/NV once a generator has demonstrated satisfactory implementation of the NTSWAC. Approval of waste streams or waste generators may be suspended if the generator's documentation or wastes do not meet the NTSWAC requirements. 
Discussion held with NTS (Ref. 16) indicated that there is a great need for acceptable LLW containers/packages for use by LLW generators. This discussion suggested that 14TTW cylinders filled with LLW may be acceptable for disposal of Area 3. Depending on the density of the LLW form placed in the 14TTW cylinders, a disposal package could weigh as much as $30,600 \mathrm{lbs}$. (13.8 MT). NTS would be able to handle packages weighing this much provided they were given sufficient advance notice.

\section{AVAILABILITY OF 14TTW CYLINDERS AND LLW FORMS}

The following are three types of materials as needed to demonstrate the use of 14TTW cylinders as LLW disposal containers:

- two 14TTW cylinders that have been emptied, washed, and are in good condition (not damaged or corroded);

- $28,000 \mathrm{lb}$ of $\mathrm{U}_{3} \mathrm{O}_{8}$ that meets LSA and NTSWAC requirements; and

- $139 \mathrm{ft}^{3}$ of soil that meets LSA and NTSWAC requirements.

Several cylinders meeting the requirements for a demonstration activity exist at the Paducah, KY, site. BJC has washed all the cylinders the USEC safety basis will allow at Paducah (Ref. 10). Based on this information fru USEC, it is reasonable to assume two cylinders could be obtained from the cylinders at Paducah and used for demonstration purposes.

The Uranium Management Center (UMC) at Portsmouth, $\mathrm{OH}$, was contacted to determine the availability of $\mathrm{U}_{3} \mathrm{O}_{8}$ for use in demonstrating the use of 14TTW cylinders as LLW disposal containers (Ref. 18). A sufficient quantity of material exists at Portsmouth for demonstration purposes. However, the $\mathrm{U}_{3} \mathrm{O}_{8}$ currently available is slightly enriched, not depleted. A radiochemical analysis is necessary to ensure LSA limits are not exceeded. UMC also confirmed that a sufficient amount of soil that meets the needs of this demonstration was available at Portsmouth.

\section{REFERENCES}

1. Public Law 105-204 (page 112, STAT. 681), $105^{\text {th }}$ Congress, approved July 21, 1998.

2. U.S. Department of Energy, Final Plan for the Conversion of Depleted Uranium Hexafluoride as Required by Public Law 105-204, July 1999.

3. U.S. Department of Energy, Draft Depleted Uranium Hexafluoride Materials Use Roadmap, September 1, 2000.

4. American Society of Mechanical Engineers, Boiler and Pressure Vessel Code, Sect. VIII, Div. I, Sect. XI, ASME New York, 1992.

5. D. G. O'Connor et al., Draft Comparative Evaluation of One-Site vs Two-Site Options for Depleted Uranium Hexafluoride Conversion, ORNL/TM-1999/116, Oak Ridge, TN, April 2000.

6. G. M. Wilkowski, N. D. Ghadiali, R. Mohan, and C. R. Miele, Final Report on Structural Integrity Analysis of UF 6 Storage Cylinder to Department of Energy Oak Ridge Field Office, Battelle, Columbus, OH, October 16, 1992.

7. J. R. Kirkpatrick, C. K. Chung, J. L. Frazier, and D. K. Kelley, Methods and Results for Stress Analyses on 14-Ton, Thin-Wall Depleted UF Cylinders, ORNL/TM-13308, Oak Ridge, TN, October 1996.

8. Bechtel Jacobs Company, LLC, Procedure Number FS-B-203 Rev. 1, Weld Patch Repair of Large Diameter DOE UF, Cylinders, June 8, 2000. 
9. "Part 173-Shippers-General Requirements for Shipments and Packagings, Subpart I-Class 7 (Radioactive) Materials," Code of Federal Regulations, Title 49, National Archives and Records Administration, Washington, DC, 1998.

10. M. S. Taylor, Bechtel Jacobs Company, LLC, East Tennessee Technology Park, Oak Ridge, TN, Personal communication, September 28, 2000.

11. The UF 6 Manual: Good Handling Practices for Uranium Hexafluoride, USEC-651, Rev. 8, United States Enrichment Corporation, January 1999.

12. Eatth Manual, U.S. Bureau of Reclamation, Denver, CO, 1974.

13. W. K. Duerksen, J. R. Hightower, and J. R. Trabalka, "Selection of Optimum Storage for Depleted Uranium, Appendix B," in Depleted Uranium Storage and Disposal Trade Study Summary Report, ORNL/TM-2000/10, January 2000.

14. J. W. Durbin et al., The Engineering Analysis Report for the Long-Term Management of Depleted Uranium Hexafluoride, UCRL-AR-124080, Vol. 1, Ref. 2, May 1997.

15. A. G. Croff et al., Assessment of Preferred Depleted Uranium Disposal Forms, ORNL/TM2000/161, Oak Ridge, TN, June 2000.

16. M. B. Noland, Nevada Test Site, Personal communication, September 25, 2000.

17. "Nevada Test Site Waste Acceptance Criteria," DOE/NV-325, NTSWAC, Rev. 2, Waste Management Division, 1999.

18. C. W. Sheward, Bechtel Jacobs Company, LLC, Portsmouth Uranium Management Center, Portsmouth, $\mathrm{OH}$, Personal communication, September 28, 2000. 


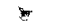

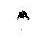

( 


\section{INTERNAL DISTRIBUTION}

1. J. M. Begovich

2. J. B. Clendenen

3. A. G. Croff

4. L. R. Dole

5. J. J. Ferrada

6. M. J. Haire

7. J. R. Hightower, Jr.

8. D. W. Lee
9. G. T. Mays

10-14. D. G. O'Connor

15-19. A. B. Poole

20. J. H. Shelton

21. K. A. Williams

22. Central Research Library

23. ORNL Laboratory Records-RC

24-25. ORNL Laboratory Records-OSTI

\section{EXTERNAL DISTRIBUTION}

26. L. D. Boggs, DOE, Oak Ridge Operations Office, 200 Administration Road, Oak Ridge, TN 37831 .

27. S. R. Martin, DOE, Oak Ridge Operations, P.O. Box 2008, Oak Ridge, TN 3783 1-6269.

28. M. B. Noland, Radioactive Waste Acceptance Program Manager, Bechtel Nevada, P.O. Box 98521, Las Vegas, NV 89193-8521.

29. R. R. Price, U.S. Department of Energy, NE-20, Room E-461, 19901 Germantown Rd., Germantown, MD 20874-1290.

30. C. W. Sheward, Bechtel Jacobs Company, LLC, MS-7550, P.O. Box 900, Piketon, OH 45661 .

31. P. I. Stumbo, DOE, Oak Ridge Operations Office, 200 Administration Road, Oak Ridge, TN 37831.

32-36. K. M. Shaw, U.S. Department of Energy, NE-30, Room E-475, 19901 Germantown Rd., Germantown, MD 20874-1290.

37-41. A. F. Tavares, U.S. Department of Energy, Office of Uranium Hexafluoride Management, NE-30, Room 1I-062, 1000 Independence Avenue, SW, Washington, D.C. 20585.

42. M. S. Taylor, Bechtel Jacobs Company, LLC, P.O. Box 2003, MS-7239, Oak Ridge, TN 37831-7239.

41. D. K. Wierwille, DOE, Oak Ridge Operations Office, Room G 120-3, Federal Office Building, 200 Administration Road, Oak Ridge, TN 37831. 
